\title{
Benedetta Craveri, Gli ultimi libertini
}

\section{Vittorio Fortunati}

\section{(2) OpenEdition}

\section{Journals}

\section{Edizione digitale}

URL: http://journals.openedition.org/studifrancesi/5339

DOI: 10.4000/studifrancesi.5339

ISSN: 2421-5856

\section{Editore}

Rosenberg \& Sellier

\section{Edizione cartacea}

Data di pubblicazione: 1 dicembre 2016

Paginazione: 530

ISSN: 0039-2944

\section{Notizia bibliografica digitale}

Vittorio Fortunati, «Benedetta Craveri, Gli ultimi libertini », Studi Francesi [Online], 180 (LX | III) | 2016,

online dal 01 janvier 2017, consultato il 18 septembre 2020. URL : http://journals.openedition.org/ studifrancesi/5339; DOI : https://doi.org/10.4000/studifrancesi.5339

\section{Questo documento è stato generato automaticamente il 18 settembre 2020.}

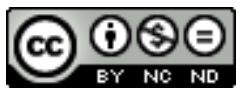

Studi Francesi è distribuita con Licenza Creative Commons Attribuzione - Non commerciale - Non opere derivate 4.0 Internazionale. 


\title{
Benedetta Craveri, Gli ultimi libertini
}

\author{
Vittorio Fortunati
}

\section{NOTIZIA}

BENEDETTA CRAVERI, Gli ultimi libertini, Milano, Adelphi, 2016, 620 pp.

1 I libri di Benedetta Craveri sono l'esempio di come il rigore della ricerca si possa unire al talento narrativo, di come un saggio scientifico possa essere una lettura avvincente anche per un pubblico non specialistico. Dopo La civiltà della conversazione (2001), Amanti e regine (2005) e Maria Antonietta e lo scandalo della collana (2006), la studiosa continua la sua esplorazione della Francia settecentesca e rievoca il periodo che precedette la Rivoluzione attraverso alcune figure che, per certi versi, ne sono il simbolo: uomini, cioè, nella cui personalità la spregiudicatezza del comportamento coesisteva con la curiosità intellettuale e con l'apertura alle nuove idee. Erano, come dice il titolo, libertini nei due significati del termine: quello più corrente di individui dediti alla ricerca del piacere e quello più antico, più nobile, di liberi pensatori.

2 Sono sette i personaggi di cui l'autrice descrive il carattere e le vicende: il duca di Lauzun, che fu agente dello spionaggio francese in Gran Bretagna, combattente per l'indipendenza americana e governatore del Senegal; il visconte di Ségur, che scrisse saggi, romanzi e pièces teatrali; il conte suo fratello, che come ambasciatore di Sua Maestà in Russia entrò a far parte della cerchia di Caterina II; il duca di Brissac, collezionista d'arte, massone, filantropo, ecologista ante litteram; il conte di Narbonne, forse figlio illegittimo di Luigi XV, che fu tra i pochi aristocratici a studiare seriamente l'economia politica e che aderì alla Rivoluzione; il cavaliere di Boufflers, collaboratore a diciannove anni dell'Encyclopédie e, autore, dopo diverse avventure galanti, del «più bel carteggio amoroso in lingua francese del Settecento» (p.182); il conte di Vaudreuil, ottimo attore dilettante e brillante conversatore, mecenate e cultore dell'arte antica. Con loro rivivono, in queste pagine, molti esponenti del mondo politico e culturale che, per vari motivi, ne incrociarono l'esistenza: da Maria Antonietta a Madame du Barry, da Chamfort a Laclos, da Mirabeau al principe di Lignes, da Élisabeth Vigée Lebrun a 
Madame de Staël, per citarne solo alcuni. Si compone così un grande affresco, il paesaggio del morente ancien régime: epoca in cui intrighi amorosi e intrighi di corte, avventure da romanzo e avvenimenti storici si intrecciavano e si sovrapponevano, quando non coincidevano del tutto.

3 Il destino dei protagonisti (come quello delle loro amanti e dei loro amici) è oggetto del capitolo più lungo del volume («1789»), in cui è narrato molto bene il susseguirsi vorticoso degli eventi negli anni della Rivoluzione, dalla convocazione degli Stati Generali fino al Terrore. Dei sette libertini, ci fu chi salì sul patibolo, chi emigrò, chi attraversò indenne il succedersi dei diversi regimi. Ognuno, però, rimase fedele alla propria natura (o, forse, al proprio personaggio) di raffinato dilettante della politica, della cultura e della vita.

4 Le numerose recensioni che hanno accolto, su quotidiani e periodici, l'uscita di Gli ultimi libertini ne hanno messo in rilievo il carattere "romanzesco": la presenza di aneddoti gustosi, la suspense che accompagna lo svolgersi delle vicende, la possibilità per il lettore di immergersi nell'atmosfera di un'epoca. Senza sottovalutare le suddette qualità, ci pare più utile, in questa sede, sottolineare l'abbondanza degli stimoli che lo studioso può trarre dalla lettura di quest'opera: in certi casi, è la stessa autrice che suggerisce esplicitamente (e generosamente) nuove piste e possibili approfondimenti. 